\title{
A Review of Mindfulness Improves Decision Making and Future Prospects
}

\author{
Si Liu, Yaozhong Liu, Yakun Ni \\ School of Management, Jinan University, Guangzhou, China \\ Email: 562968361@qq.com
}

How to cite this paper: Liu, S., Liu, Y. Z., \& Ni, Y. K. (2018). A Review of Mindfulness Improves Decision Making and Future Prospects. Psychology, 9, 229-248. https://doi.org/10.4236/psych.2018.92015

Received: January 5, 2018

Accepted: February 20, 2018

Published: February 23, 2018

Copyright $\odot 2018$ by authors and Scientific Research Publishing Inc. This work is licensed under the Creative Commons Attribution International License (CC BY 4.0).

http://creativecommons.org/licenses/by/4.0/

\begin{abstract}
With the popularity of mindfulness training among different groups of people, more and more attention has been paid to the positive role of mindfulness. In particular, the improvement of mindfulness on decision-making has been respected by the elite management and practitioners in different industries. There are also different forms of experimental paradigms for different types of decision-making behaviors in research methods. Both behavioral evidence and imaging evidence show that mindfulness training can improve decision-making, both under the social and non-social conditions. Mindfulness training was predominantly driven by an "emotional" system, manifested by an active medial prefrontal cortex, whereas the latter was not dominated by a "rational" system of decision-making processes; on the contrary, posterior insular and thalamic regions with emotional function were more active. Therefore, the emotional system throughout the mindset training affects the whole process of decision-making. In addition, mindfulness affects other possible factors such as attention, compassion, and cognitive control in the decision-making process. At last, based on the existing research deficiencies, this paper analyzed future prospects from the aspects of research methods, research contents and theoretical construction, in order to provide references for future research in this field.
\end{abstract}

\section{Keywords}

Mindfulness, Mindfulness Training, Decision Making, Mechanism, Review

\section{Introduction}

Decision making is the process of selecting and implementing a program or strategy based on individual values and preferences among multiple alternatives. (Rilling \& Sanfey, 2011). The process of decision-making is often characterized 
by competition and intuition as the competition between the two, it is a social activity, involving all aspects of social life, small to where to play, as much as the formulation of national policies, is related to decision-making activities. Simon, a U.S. management scientist, even suggested that management is a policy making (Simon, 2001). Business performance depends largely on the decision-making performance of top management teams. A range of issues such as corporate performance and business ethics in modern enterprises are tied to leadership decision-making (Eisenbeiss, Knippenberg, \& Fahrbach 2015). Some are based on incorrect information or decisions. The premise of the decision-making will lead to enterprises into trouble or even endanger the survival of enterprises. Therefore, decision-making as a basic human psychological activity, in daily life and work management is very important. Under the background of rapid economic and cultural development, it is a very promising subject to study the dramatic increase of choices and how people make scientific and rational decisions.

At present, mindfulness to enhance decision-making power has become a hot topic that researchers are increasingly concerned about. In business, decisionmaking is one of the cores of management activities, how decision-making is generated, and how it is all about management (Simon, 1987). And the spread of "Mindfulness and Heat" around the world was also the cover of Time Magazine, launched in February of 2014 by "Revolutionary Mindfulness," which made mindfulness training popular among CEOs and executives (Cheng, 2016) as well as practitioners in a variety of industries such as lawyers (Blatt, 2002), nursing staff (Pipe et al., 2009) and many more. Mindfulness is widely circulated across industry sectors and is even popular at different ages, including children and students (Waters et al., 2015), the elderly (Fiocco \& Mallya, 2015). A series of studies have shown that mindfulness training can not only bring about the change of state (state of mindfulness), but also continue to change one's personality (trait of mindfulness) (Cahn \& Polich 2006).

Mind training also sets off a wave of research in the field of psychotherapy, and mindfulness-based intervention training is called the "third wave" of cognitive behavioral therapy (Miao \& Wang, 2013). Mindfulness training, as a means of improving the state of life, can help individuals have a clear mind and develop clear thinking, providing solutions to problems or making scientific and rational judgments and decisions from multiple choices. Mindfulness Training Interventions Individuals can also contribute to improving decision-making quality through awareness of their attention and emotions (Panno et al., 2013). Many executives and CEOs (Apple founder-Steve Jobs, Bridgewater founder-Ray Dalio, the Former president of Swiss National Bank-Philipp Hildebrand, etc.) have long insisted on mindfulness meditation, and many top global enterprises (General Mills, Ford Motor Company, Tupperware Company, etc.) have also gradually introduced mindfulness-training related courses and practice tools to help employees achieve calm thoughts, relieve stress and concentration effects, and even help enterprises cultivate outstanding leaders. Mindfulness training 
can therefore help business members improve the accuracy of business decisions and help companies avoid expensive investment mistakes.

Throughout the study of psychology and management at home and abroad, the review of the theme of mindfulness mostly focuses on the analysis of the concept of mindfulness, the psychology of mindfulness and the mechanisms such as the brain mechanism or biological mechanism. The concept of mindfulness on a specific area Feeling and emotions (Duan, 2014; Wang \& Huang, 2011; Wang \& Jiang, 2016; Xu \& Liu, 2013; Chen et al., 2011; Tang et al., 2015). In view of the positive results of positive research and decision-making in foreign countries, such studies have a wide range of application value in work and real life, but there is still a lack of relevant retrospective research on this topic at home and abroad, and there is a lack of unity in empirical research Operation standards and other issues. Therefore, systematically reviewing the related research of mindfulness and decision-making is helpful to analyze the research achievements in different phases and deeply analyze the training effect of mindfulness on all kinds of decision-making, and constructively absorb the frontier research on such topics in localization research Advanced and cultural essence to provide relevant reference. Based on the review of a large number of literatures, this dissertation mainly analyzes mindfulness and its related core concepts, and reviews the training effects of mindfulness training on different types of social decision-making and non-social decision-making respectively, and discusses its mechanism. On this basis, the author puts forward the deficiencies of the existing research and prospects the future research direction in order to provide reference for the future research.

\section{Mindfulness and Its Development and Application}

\subsection{The Origin and Conceptual Definition of Mindfulness}

The concept of "mindfulness" first originated from the oriental meditation culture, which dates back to the teachings of Buddha Sakyamuni 2500 years ago. It has developed from the practice of meditation, meditation and enlightenment. It is one of the eight pathways of Buddhism practice. Mindfulness is also translated as "Mind Awareness," as Pali was called Sati, and for the first time in 1921 it was translated into English mindfulness. The original meaning was attentiveness, concentration, concentration, and attention or observation. Mindfulness is "a purposeful, non-judgmental method of focusing attention on the moment (present-day experience)" and usually requires the individual to observe at some distance what they think and feel at this moment, but not to judge it well Bad or wrong (Kabat, 2003).

In addition to Professor Kabat's classic definition of mindfulness, other psychologists of different orientations proposed different interpretations of mindfulness. Cahn and Polich (2006) view the concept of mindfulness as a static state or trait that believes that mindfulness is both a special state of mind that alters sensation, cognition, and self-referencing, and that is, a lasting change in state of 
consciousness Trait. Tate (2007) argues that mindfulness consists of five components: conscious attention, reduction of self-dialogue, non-judgment, failure to respond, and a series of values of philosophical ethics and treatment orientation. Shapiro and Carlson (2006) put forward two kinds of orientations of mindfulness and states of mind, which are recognized by the majority of scholars. They propose: 1) Mindfulness, when used as a noun, refers to a trait, namely Mindfulness Perception, which is a continuous consciousness and depth perception manifested as inner freedom; 2) when mindfulness is a verb, Refers to a state, namely Mindfulness Training, which is a conscious perception of all present experiences in an open, receptive, non-judgmental way.

This article adheres to the consensus of most scholars: Mindfulness is both a trait and a technological tool. With "mindfulness" as its core, this paper reviews the related research on mindfulness (mindfulness awareness) and state mindfulness (mindfulness training). In this paper, we refer to mindfulness as "idiosyncrasy" or "mindfulness training", respectively, based on the scholarship's specific research, but when discussing the conclusion, we refer to the term "mindfulness" as the cognitive phenomenon itself, or the general term for mindfulness and mindfulness training, and the term "mindfulness training" refers to the general term for different techniques for individuals to gain the level of mindfulness.

\subsection{Differentiating and Analyzing the Related Concepts of Mindfulness}

Although mindfulness originated from traditional meditation, it has gradually been applied to all aspects of work and life. Therefore, analyzing mindfulness and related concepts helps us to analyze the core meaning of mindfulness, distinguishing it from other concepts and laying the foundation for future research.

Western scholars frequently used confusion or meditation in both research and meditation, which brought some obstacles to the unification and norms of mindfulness research. The two exist interrelated, but they are completely different concepts. Internationally, it is generally accepted that meditation is divided into two categories: mindfulness/open monitoring and concentrative/focused attention, depending on the direction of attention (Cahn \& Polich, 2006). Therefore, we can clearly draw the relationship between the two: mindfulness belong to meditation, is a type of meditation. Mindfulness meditation, along with other types of meditation, such as loving-kindness meditation (Lippelt et al., 2014) and Visual meditation (Standaert, 2015), make up the category of meditation.

In addition, according to previous studies found that mindfulness and concentration, there are many similarities and differences. Concentration, as a basis for mindfulness affecting human function, can experience strong concentration in mindfulness. However, concentration is only one of the elements of mindfulness. Mindfulness requires not only concentration but also individual awareness. Focus on the moment, and accept other elements without judgment (Zhang et 
al., 2017). There are many similarities between " mind wandering " and "mindfulness", both of which emphasize the mental state in which individuals experience concentration and devotion (Csíkszentmihályi, 2008), but mindfulness require the awareness of the individual to be present and at this moment; The mind wandering is more of a state that can be realized during the retrospective period (Foster \& Lloyd, 2007). Because individuals in the state of mind flow in and forget themselves, they easily lose their awareness of self-awareness and surrounding space and time.

\subsection{Distinguishing Mindfulness Training and Mindfulness Meditation}

Mindfulness Training As mentioned above, it is a method of obtaining mindfulness in the state of mindfulness classification. As early as the 1970s, Kabat-Zinn learned the essence and nutrition of oriental meditation and created effective Mindfulness-Based Stress Reduction (MBSR) in clinical psychiatry. Subsequently, researchers also developed a large number of psychotherapy based on mindfulness training: mindfulness therapy (Mindfulness-based Cognitive Therapy (MBCT), Dialectical behavior therapy (DBT), Acceptance and Commitment Therapy (ACT) and others (Miao \& Wang, 2013).

Mindfulness meditation $(\mathrm{MM})$ is an important method used to practice mindfulness. It is also the core technique of mindfulness training. It mainly includes practice methods such as Zen and Vipassna (Kabat-Zinn, 2003; Ivanovski \& Malhi, 2007). Therefore, we can clearly draw the relationship between them: mindfulness training is based on the core techniques such as mindfulness meditation, and mindfulness meditation is a practice method under the mind training. The purpose of this method is to practice mindfulness and achieve Clarification and awakening of thinking. Mindfulness Training is also due to positive meditation and other techniques such as meditation, body scans, breathing space for three minutes, and mindfulness and yoga, which have greatly facilitated the wide spread of mindful rituals among different groups (Miao \& Wang, 2013).

\subsection{The Development and Application of Mindfulness}

After the integration of mindfulness and modern psychology, it gradually becomes religious and develops a scientific and systematic psychological training method, which is also gradually extended from clinical application to real life. In particular, with the continuous development and innovation of neuroimaging research in recent years, behavioral and neuroimaging studies have also provided evidence for the positive impact of mindfulness (Tang et al., 2007).

In recent years, researchers have integrated integrative body-mind training (IBMT) with many important elements of mind training, such as concept of breathing, psychological intention and mindfulness according to different research purposes and practical needs. Time can also be shortened to 1 - 6 weeks and is therefore favored (Tang et al., 2007). Integrative medicine (IM) combines 
elements such as meditation, yoga and respiratory training to address health care issues (Saatcioglu, 2013); mindfulness and rebus therapy is also a combination of mindfulness meditation and cognitive behavior Special therapy for substance addicts formed by resuscitation (Wang \& Zhao, 2016), and mindfulness techniques based on different groups of special training methods have made mindfulness widely used in the clinical field.

The potential for mindfulness in the workplace is huge (Good et al., 2016). First, there is a decrease in the level of burn-in in mindfulness and mindfulness based training and self-reporting (Flook et al., 2013), decrease in perceived stress (Ruocco \& Direkoglu, 2013), decrease in negative emotions (Roche et al., 2014) Promoting job involvement (Malinowski \& Hui, 2015) and a series of outcomes such as enhanced employee well-being (Eberth \& Sedlmeier, 2012) are closely linked, and in particular, righteous leadership is also tied to all aspects of employee well-being (Roche et al. 2014; Reb \& Narayanan, 2014). Second, in workplace behavior, mindfulness in the workplace is not only positively correlated with individual job performance (Dane, 2011), but mindfulness also have a positive effect on team performance (Cleirigh \& Greaney, 2015). Moreover, mindfulness training can also improve working memory and GRE scores by reducing mind wandering (Mrazek et al., 2013). In addition, mid-level managers who pass mind-nurturing training show better team control than the control group (Shonin et al., 2014) or positive changes in leadership effectiveness (Wasylkiw et al., 2015). In contrast to mindfulness training, individual ideals of employees are significantly correlated with low-negativity (Krishnakumar \& Robinson, 2015), while leader ethos and organizational citizenship are relevant (Red et al., 2014). Finally, beyond the workplace, the higher the level of mindfulness in individual traits, the better the quality of sleep (Allen \& Kiburz, 2012). Therefore, increasing the level of daily mindfulness can not only promote the quality of sleep and sleep, but also promote the work-family balance (Michel et al., 2014).

The above series of studies have successfully proved that mindfulness are widely used in the workplace in addition to the clinical field, and that research teams introduce mindfulness to the army and the police system (Wang \& Jiang, 2016). Nowadays, mindfulness training techniques are gaining in popularity both as an adjunct to the clinical management of physical and mental health conditions or as a lifestyle choice.

\section{The Impact of Mindfulness on Decision Making}

\subsection{The Research Methods of Mindfulness on Decision Making}

With the deepening of mindfulness and decision-making research, its research methods are also maturing. Originally, Park et al. (2006) used electronic public participation (EPP) to investigate the impact of residents' meditations and meditation on nuclear-related decisions through online voting to analyze the public low-radioactive waste disposal at the National Seoul National University campus 
Opinions on facility siting are case studies, but electronic public participation (EPP), as a newly emerging open technology, can be used in other decision making processes. Kirk et al. (2011) used a relatively straightforward horizontal design, so it is impossible to compare the behavioral differences before and after starting to study mindfulness. Without this information, we cannot be sure that the actual behavior of mindset practitioners benefits. Subsequently, Shapiro et al. (2012) used a single-tracing experiment design in investigating the impact of mind-bending decompression therapy on ethical decision-making. In addition, while most studies have taken a more standardized 8-week mind-bending decompression regimen (MBSR), other studies have used only 15-minute recording meditation to guide individuals' mindfulness, as well as the simple combination of scholarship with other forms of training For example, meditation) (Shapiro et al., 2012), but different ways of mindfulness training inevitably lead to differences in outcomes.

The impact of early mindfulness on decision making mostly adopts singlegroup design. Due to the lack of comparison between control groups, it cannot really test whether the effect of mindfulness stems from the changes brought about by training or the effects of individual maturation. In recent years, researchers mainly used comparatively rigorous experimental group to control the experimental design before and after test (Mirams et al., 2013; Ruedy \& Schweitzer, 2010; Hafenbrack et al., 2014).

There are two types of research tasks on decision-making: the discount task and the gambling task. There are two types of discount task: the discount task and the probability discount task. The task of gambling has the Iowa gambling task, the dice gambling task, the Cambridge gambling task, Gambling tasks (Liu et al., 2014) and corresponding experimental paradigms for different decision types such as SSDT (Mirams et al., 2013) and ethical dilemmas (Shapiro et al., 2012), classic business finance testing in business decisions (Hafenbrack et al., 2014) and others. These relatively rigorous experimental design and targeted experimental tasks and experimental paradigms not only improve the measurement accuracy of decision-making level, but also improve the verification of the effect of mindfulness on decision-making.

In addition, the Carbonless Anagram Method (CAM)) was introduced into the area of ethical decision-making for mindfulness training. Compared with the general problem of moral dilemma, it can record the unethical behavior at the individual level in an obscure way and can also be researched in a small group in the laboratory (Ruedy \& Schweitzer, 2010). Therefore, compared with the questionnaire measurement, CAM effectively eliminates the practice effect, has better reliability and ecological validity, and is more suitable for team measurement.

\subsection{The Intervention Effect of Mindfulness on Decision Making}

We assume that the effect of mindfulness may not be limited to those cognitive and emotional aspects that have the preconditions of advanced decision-making, 
but also extend to the decision-making process. Research evidence also shows that mindfulness play an important role not only in pro-social behaviors that reduce economic decision-making bias and social decision-making, but also clinically as effective tools to reduce drug abuse and alcohol addiction (Breslin et al., 2002). These diseases are related to impulsive behaviors (e.g., adventurous) and second-best decisions (Keng et al., 2011). All these studies show that mindfulness can improve decision-making, both in social and non-social conditions.

Based on the available literature, we divide decision-making into two categories: social and non-social. Social decision research focuses on interaction, making decisions based on peer choices and other people's preferences (Sanfey, 2007), rather than social decision research focusing on personal decision making based on one's beliefs, values, and preferences. The following separately from the social decision-making and non-social decision-making to explore the experience of mindfulness will promote the decision-making process.

\subsubsection{The Influence of Mindfulness on Social Decision Making}

The impact of mindful meditation on social decision-making is mainly focused on the areas of fair assessment, moral decision-making, pro-social behavior (altruistic behavior) and others.

Assessing the fairness of social interaction is an important aspect of social behavior. The ultimatum game is often used to assess fair sensitivities in which two people are involved and one is a respondent. Proponents will pay part of the money to the respondents (uniform or non-uniform) and both will receive a corresponding benefit if the respondent agrees to accept it; no one will receive any benefit if the respondent declines (Crockett et al., 2010). Kirk et al. (2011) used the ultimatum game and found that mind-set training groups were more willing to accept unfair decisions than the control group. The control group was active in the anterior region of the insular region when it was unfairly proposed, suggesting that the region may be an important neural basis for denying social interaction; in contrast, the righteous practitioner showed a decrease in the activity of superior afferent features in the anterior forebrain and a decrease in the posterior insula Low-level endoreceptor characterization of the increased activity. That is to say, there are differences in the brain mechanisms between the control group and the mindset training group in rejecting social interaction, and the mindset training group can separate the negative emotions and behaviors more than the control group. Based on these findings, we can make it clear that continuous mindfulness training can make individuals more willing to accept unfairness by adjusting their emotions.

Moral decision-making is often the scene of social life choice. Ruedy et al. (2010) used a 15-minute focused breathing recording to manipulate the state's mindfulness and did not significantly influence ethical decision making. Subsequent Shapiro et al. (2012) also found no significant changes in moral reasoning from baseline to MBSR training; however, follow-up after 2 months showed significant moral reasoning and decision making The change. In addition, David- 
son et al. Also found that follow-up after 4 months in mindfulness training practices has increased the level of ethical decision making (Davidson et al., 2003). This proves from the side that mindfulness is a skill that needs to be developed through practice and daily training, and that moral decision-making is more stable than social decision-making in general and can take a certain amount of time to be improved.

In addition to these laboratory studies, some researchers used more ecologicallyeffective research methods to investigate the impact of mindfulness on real-time interpersonal interaction. The results showed that experimental groups participating in a week of mindfulness training programs were more likely to give up their Seat for people with physical disabilities (Condon et al., 2013). Mindfulness Interpersonal interaction in the workplace is characterized by leadership mindfulness or attitude mindfulness, and teamwork affecting employee behavior, while mindfulness in life may be improved through more attention to others, better communication, less conflict, more sympathy The relationship between intimate partners (Reb \& Narayanan, 2014; Good et al., 2016). In addition, the researchers also examined the impact of mindfulness on implicit prejudice, and studies by Lueke and Gibson (2015) validated experiments that ten minutes of mindfulness recording training compared to a control group that listened to a 10-minute natural history recording Group, age and racial prejudice are significantly lower. Mindfulness training promotes the social harmony by inducing the automation relationship between prejudice and prejudice, thus significantly weakening the influence of invisible prejudice. These results all suggest the necessity of carrying out mindfulness training in real life in order to increase social altruistic behavior.

In summary, the above studies show that the positive effects of consistency in short-term and long-term mindfulness training include fair assessment, ethical decision-making, pro-social behavior and inter-group bias, and mindfulness training can be achieved by adjusting executive control, reward handling, emotional management, etc. in the decision-making process Psychological activities to promote social decision-making.

\subsubsection{The Influence of Mindfulness on Non-Social Decision-Making}

In the field of non-social decision-making, most researchers use the paradigm of game theory and behavioral economics to investigate economic preferences and decision-making bias in the context of personal and interactive situations. Among them, the influence of mindfulness on non-social decision-making includes risk taking, impulsive gambling, Negative bias and sunk cost bias.

In general, risk taking refers to a tendency to engage in actions that may be harmful or dangerous, but at the same time, it can also create opportunities for positive results. Especially in the economic arena, risk is defined as the situation after failed gambling, increasing the need for risk-taking and unease when losing money (Winters et al., 2002). Therefore, gambling decisions are generally based on the Georgia Gambling Task (GGT; Goodie, 2003), which is reflected in the 
willingness to take too much or to take risks, and Iowa, which assesses the risk appetite for uncertainty, rewards and penalties Iowa Gambling Task, IGT; Lakey et al., 2007b. Lakey et al. (2007a) used GGT and IGT tasks $(\mathrm{N}=309)$ in college student samples to explore the impact of idiomatic mindset on adventurous behavior. They found that an increase in mindfulness could signal a decrease in the severity of gambling outcomes and an increase in decision adaptation. In contrast, individuals with low levels of mindfulness may take adverse decisionmaking behaviors such as gambling and drug abuse (Bowen et al., 2009). The Alfonso et al. (2011) survey further validates long-term mindfulness training in combination with targeted management training that can help drug abusers (who are considered clinically significant in executive function and decisionmaking deficiencies) to make decision-making Adaptive decision making. Scholars' discoveries have shown that mindfulness can help to improve the underlying effects of impulsive gambling inhibition, decision-making dysfunction and drug addiction.

Negative biases tend to weigh negative information, events or emotions heavier than positive (Rozin \& Royzman, 2001), and people are highly susceptible to prejudice in their lives. In Kiken and Shook (2014), the use of standardized 10-minute mind-breathing training reduced the emphasis on negativity and the other decreased the negative bias after 175 college students participated in the simplest 15-minute mindfulness-guided breathing exercise, And added positive judgments in attitude formation tasks (Kiken \& Shook, 2011). These results show that mindful training intervention can significantly improve the propensity for positive information and judgment.

Sunk cost bias is the propensity to pursue failed efforts once money, hard work, or time has been invested (Maréchal, 2010). People caught in the sunk cost bias, even if they know that sustainability is not the best option, may be linked to escalating promises, distressed expectations and regrettable misgivings (Tversky \& Kahneman, 2016; Wong \& Kwong 2007). Hafenbrack et al. (2014) investigated the effect of short-term mindfulness training on sunk cost bias and found that mind-nurturing training reduces the sunk cost by reducing the negative emotional state and reducing the sunk cost by deviating the individual's temporal focus from the past and the future. Individuals can improve their mind-set by practicing mindfulness training and their ability to resist sunk cost variances, improving the accuracy of individual business decisions and helping companies avoid expensive investment mistakes (Hafenbrack et al., 2014).

The above series of studies show that mindfulness can reduce non-social decision-making behaviors such as risk taking, impulsive gambling, negative bias and sunk cost deviation, and mindfulness is adjusted by controlling risk response, avoiding habitual reaction, adjusting time focus and reducing negative emotions Decision-making process.

\subsubsection{The Mechanism Discussion of Mindfulness on Decision Making}

At present, the study of mindfulness affecting the decision-making mechanism is 
relatively weak. With the psychological and brain mechanisms of mindful meditation, biological mechanisms, mindfulness on the emotional regulation of neurophysiological mechanisms increasingly rich, the decision-making mechanism of the impact of more urgent (Wang \& Huang, 2011; Wang \& Jiang, 2016; Chen et al., 2011).

In the process of human decision-making, "rational" and "emotional" systems control the outcome of human decisions separately (Evans, 2008). Neuroimaging evidence suggests that these two systems may have different neuronal associations. For example, intuition or emotion-driven decisions tend to increase the activity of the medial prefrontal and medial orbital frontal cortex and their striatal counterparts, however, more rational or negotiable decisions are often associated with increased lateral prefrontal and parietal Regions and their striatal counterparts (Greene et al., 2004; McClure et al., 2004). Therefore, when comparing the control group with the mind-set training group, we found a change in the cortical activity from the medial to the lateral prefrontal cortex.

Short-term and long-term mindfulness training can also lead to changes in brain activity. Short-term Mindfulness Training is involved in social decisionmaking in the medial prefrontal cortex, and in addition, relaxation training increases relaxation of the anterior cingulate cortex even during just 3 hours of mindfulness practice (Farb et al 2007; Tang et al. 2009) The medial and posterior regions of the island are activated during meditation, and Voxel-based morphometry (VBM) analyzes also show that mind precursors have greater gray matter volume in the foreland-island region than age-matched controls, reflecting Effect of long-term mindfulness training (Lazar et al., 2005; Kirk et al., 2011). All of these evidences demonstrate that the impact of mind training on decisionmaking is caused by intuition or emotion-driven systems that both increase the activity of the medial prefrontal cortex. However, some subjects in the control group also had lateral prefrontal cortex activity associated with rational decisionmaking, which may be related to the individual differences in mindfulness of the subjects themselves in the control group. In addition, the effects of mind training on decision making may not always be through the lateral and parietal lobes of the lateral lobes (Duncan et al., 2000), which are usually responsible for mathematical and logical reasoning, but rather through emotional rather than rational, meditative emotional functions Of the posterior insula and thalamic regions (Kirk et al., 2011). This also verifies that the intermediate mechanism of mindfulness training is predominantly composed of "emotional" system, which is active in the medial prefrontal cortex. The late stage is not mainly played by the "rational" system of decision-making process. On the contrary, And thalamic areas more active. Therefore, emotions affect the whole process of decision making through mindfulness (Tang et al., 2015).

Evidence from both behavioral and neuroimaging suggests that mind-boggling training can influence decision-making behavior through emotion-driven systems. Moreover, the model of mindfulness coping and the model of mindfulness 
emotion regulation also emphasize the regulation effect of mindfulness on emotions: Mindfulness plays a central role in positive cognitive reassessment, and long-term mindfulness training intervention can directly affect the attentional distribution strategy of emotion regulation. In addition, the concept of mindfulness regulates emotions by improving the regulation of the frontal lobe response to the limbic system, and mindfulness training can alter the brain structure associated with emotional processing (Chen et al., 2011). Individuals in daily life can consciously apply emotional conditioning to improve their decision-making quality based on current decision-making tasks (Panno et al., 2013). However, other studies have found that emotions affect risk perception even more than rational evaluation (Hogarth et al., 2009), And the related research also shows that even accidental emotions unrelated to current decision-making can have a significant impact on the individual's decision-making results, decision-making process and decision-making quality ( $\mathrm{Li}$ et al., 2015). Therefore, mindfulness training can promote individuals' positive emotions by adjusting their negative emotions, which is a key factor that affects individual decision-making process, quality and result.

Other research groups such as Alfonso and Shapiro also found other factors that contribute to the decision-making process during mind-setting training interventions, such as attention and self-awareness (Alfonso et al., 2011; Shapiro et al., 2012). Tang et al. (2015) summarized behavioral and neuroscience findings and proposed a model of mindfulness training: three core components including attention control, emotional management, and self-awareness, all of which work together. A number of studies have shown that mindfulness can improve decision-making skills, but whether mindfulness improve decision-making power should include other factors such as empathy, emotions and self-awareness such as compassion (Mascaro et al., 2012), cognitive control (Chambers, Lo, \& Allen, 2008) may well build the theoretical framework for the unified effect of mindfulness on decision-making, which requires more effort from future researchers.

\section{Summary and Future Research Prospects}

To sum up, some progress has been made in the study of righteous thoughts to improve decision-making, which is summarized as follows (see Figure 1).

Mindfulness is an ancient and young field; mindfulness training has long been from the clinical field to the masses. A series of studies have confirmed that mindfulness can not only improve individual emotional management, attention and cognitive control, but also improve individual decision-making ability in different fields. In general, research methods of mindfulness influencing decisionmaking are constantly improving, and there is a specific experimental paradigm for decision-making under social conditions and non-social conditions. Moreover, behavioral research combined with imaging evidence proves that mindfulness is important to social and non-social decision-making can be adjusted 


\section{Mindfulness improving decision-making}

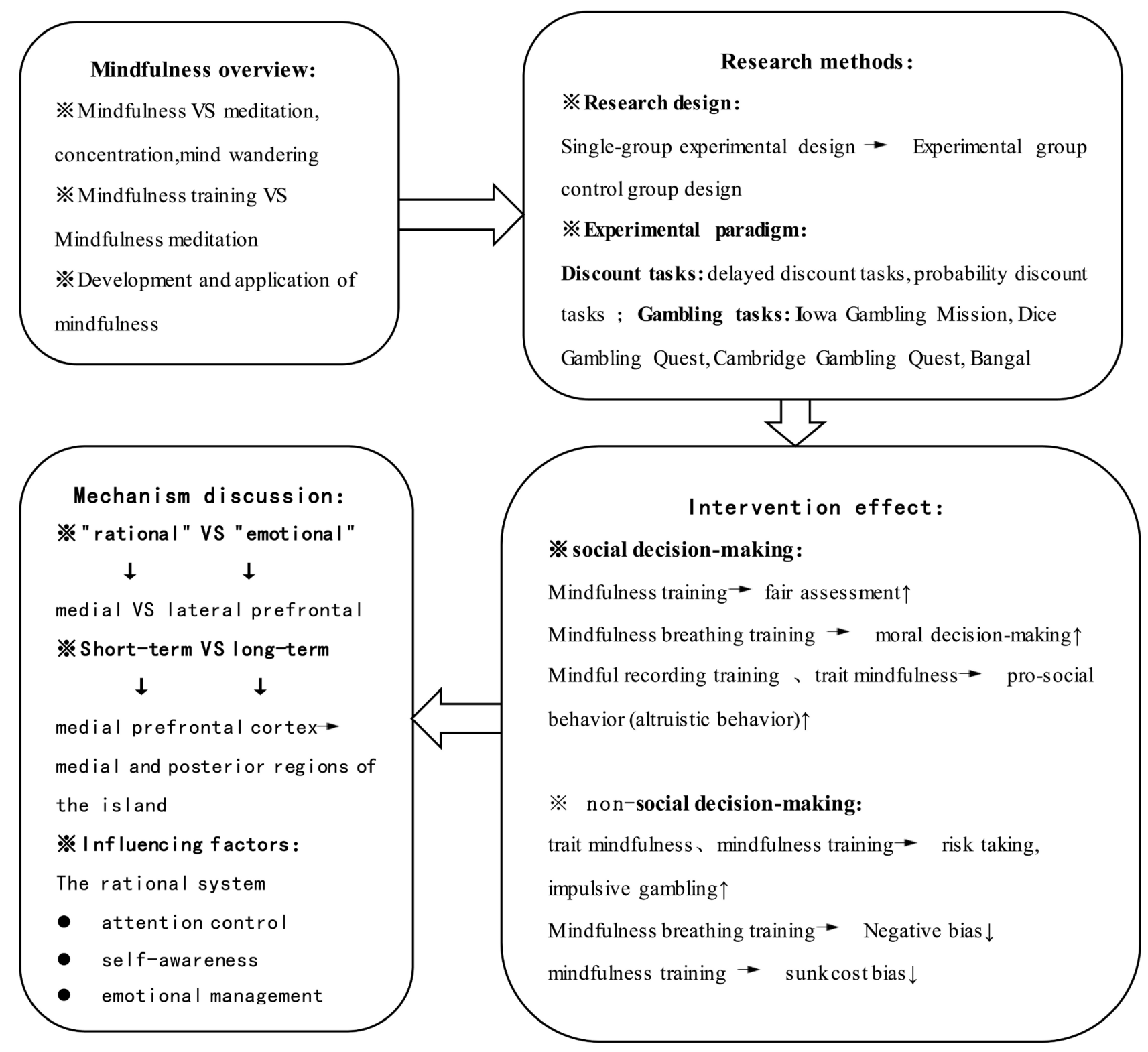

Figure 1. Mindfulness improving the decision-making framework of existing research results.

through the emotion-driven system, but its underlying neural mechanism and mechanism need to be further explored.

Future research should continue its efforts in normative training of normative operation, experimental design, mechanism of action and application value. We elaborate from three aspects: research methods, research contents and theoretical construction.

First of all, in the research methods, the influence of mindfulness on decisionmaking is mostly horizontal research and relative lack of longitudinal research. There is no empirical research on cross-experimental design (Kirk et al., 2011; 
Lakey et al., 2007). However, it is difficult for horizontal research to find the process of continuous change in the individual's mind. Only the related inferences can be made about the results, and the causal inferences need to be cautious. In the future, tracing surveys by training and control groups may be considered to explore the role of mindfulness training in decision-making at different stages of life. Secondly, the normative nature of the training process of mindfulness needs to be improved to form a set of operational norms that are applicable to the specific standards of research in China as well as cross-cultural backgrounds. Finally, in view of the different levels of mindfulness and mindfulness of individual subjects in some researches, we should try to eliminate the interference of time and individual differences as much as possible in the future.

For the first time, the current research focuses on the impact of MBSR, MBCT, and mind breathing (body scan) training on individual decision making, but there are many other forms of mindfulness training such as DBT, ACT and so on, whether different types of mindfulness training will have similar effects on decision-making remains to be explored, in addition, comparing the impact of various forms of mindfulness training on decision types, exploring the best mindfulness training methods that can enhance decision-making, as well as mindfulness training to improve the relationship between decision-making power and different brain regions structure, which specific brain regions are involved in mindfulness training in the process of decision-making, or cross-cultural research, to find the greatest extent possible for different cultures of mindfulness training methods. Second, in the future, we will consider adding the concept of righteousness, emotion, compassion, and sunk cost bias to the study of the intermediate mechanism of mindfulness and decision-making promotion. Finally, the value of mindfulness for decision-making needs to be further developed. Burke et al. point out that in today's business environment, intuitive decisionmaking is increasingly becoming a viable method. Even in some cases, it may be the main decision-making method (Burke and Miller, 1999). Therefore, whether the training of mindfulness is conducive to cultivating an individual's intuition ability, developing the potential of individual intuition and promoting the improvement of decision-making ability is also the future research direction one. In addition, promoting other types of decision-making behaviors through intuitionistic decision-making is also one of the deep-rooted mechanisms for exploring decision-making behaviors, and is conducive to its wide application in different types of decision-making tasks in daily life. There are also studies to verify that mind-nurturing training is an effective way of mitigating errors in reading, working, and even alerting tasks (mind wandering) (Mrazek et al., 2012; Smallwood \& Schooler, 2015) Inspiration from the application of mindfulness training.

In the theory construction, the western countries have put forward a more influential model of mindfulness. According to the IAA three-axis model, mindfulness is composed of three dimensions, an intention, an attention and an atti- 
tude. These three factors occur simultaneously and intertwined, resulting in the development of mindfulness (Shapiro et al., 2006). However, "Mindfulness" originates from our east and flows back to our east through the development of western psychology. It itself possesses the cultural characteristics in the western context. In the future, intercultural studies may consider using the Combined Etic-Emic Approaches (Fan et al., 2011). Combining western psychology theory with oriental specific cultural factors, the real universal psychology theory, and on this basis, explores the effect model that can completely explain the influence of mind training on decision-making.

\section{References}

Alfonso, J. P., Caracuel, A., Delgado-Pastor, L. C., \& Verdejo-García, A. (2011). Combined Goal Management Training and Mindfulness Meditation Improve Executive Functions and Decision-Making Performance in Abstinent Polysubstance Abusers. Drug and Alcohol Dependence, 117, 78-81. https://doi.org/10.1016/j.drugalcdep.2010.12.025

Allen, T. D., \& Kiburz, K. M. (2012). Trait Mindfulness and Work-Family Balance among Working Parents: The Mediating Effects of Vitality and Sleep Quality. Journal of Vocational Behavior, 80, 372-379. https://doi.org/10.1016/j.jvb.2011.09.002

Blatt, W. S. (2002). What's Special about Meditation: Contemplative Practice for American Lawyers. Harvard Negotiation Law Review.

Bowen, S., Chawla, N., Collins, S. E., Witkiewitz, K., Hsu, S., Grow, J., et al. (2009). Mindfulness-Based Relapse Prevention for Substance Use Disorders: A Pilot Efficacy Trial. Substance Abuse, 30, 295-305. https://doi.org/10.1080/08897070903250084

Breslin, F. C., Zack, M., \& Mcmain, S. (2002). An Information-Processing Analysis of Mindfulness: Implications for Relapse Prevention in the Treatment of Substance Abuse. Clinical Psychology Science \& Practice, 9, 275-299. https://doi.org/10.1093/clipsy.9.3.275

Burke, L. A., \& Miller, M. K. (1999). Taking the Mystery out of Intuitive Decision Making. The Academy of Management Executive, 13, 91-99.

Cahn, B. R., \& Polich, J. (2006). Meditation States and Traits: EEG, ERP, and Neuroimaging Studies. Psychological Bulletin, 132, 180-211. https://doi.org/10.1037/0033-2909.132.2.180

Chambers, R., Lo, B. C. Y., \& Allen, N. B. (2008). The Impact of Intensive Mindfulness Training on Attentional Control, Cognitive Style, and Affect. Cognitive Therapy and Research, 32, 303-322. https://doi.org/10.1007/s10608-007-9119-0

Chen, Y., Zhao, X., Huang, J. H., Chen, S. Y., \& Zhou, R. L. (2011). Meditating Mind's Emotional Regulation: Theory and Neural Mechanisms. Progress in Psychological Science, 19, 1502-1510.

Cheng, F. K. (2016). What Does Meditation Contribute to Workplace? An Integrative Review. Journal of Psychological Issues in Organizational Culture, 6, 18-34. https://doi.org/10.1002/jpoc.21195

Cleirigh, D. O., \& Greaney, J. (2015). Mindfulness and Group Performance: An Exploratory Investigation into the Effects of Brief Mindfulness Intervention on Group Task Performance. Mindfulness, 6, 601-609. https://doi.org/10.1007/s12671-014-0295-1

Condon, P., Desbordes, G., Miller, W. B., \& DeSteno, D. (2013). Meditation Increases Compassionate Responses to Suffering. Psychological Science, 24, 2125-2127. 
https://doi.org/10.1177/0956797613485603

Crockett, M. J., Clark, L., Hauser, M. D., \& Robbins, T. W. (2010). Serotonin Selectively Influences Moral Judgment and Behavior through Effects on Harm Aversion. Proceedings of the National Academy of Sciences, 107, 17433-17438. https://doi.org/10.1073/pnas.1009396107

Dane, E. (2011). Paying Attention to Mindfulness and Its Effects on Task Performance in the Workplace. Journal of Management, 37, 997-1018. https://doi.org/10.1177/0149206310367948

Davidson, R. J., Kabat-Zinn, J., Schumacher, J., Rosenkranz, M., Muller, D., Santorelli, S. F., Sheridan, J. F. et al. (2003). Alterations in Brain and Immune Function Produced by Mindfulness Meditation. Psychosomatic Medicine, 65, 564-570. https://doi.org/10.1097/01.PSY.0000077505.67574.E3

Duan, W. (2014). Divergences in Mindfulness Research: Concepts and Measurements. Progress in Psychological Science, 22, 1616-1627.

Duncan, J., Seitz, R. J., Kolodny, J., Bor, D., Herzog, H., Ahmed, A., Emslie, H. et al. (2000). A Neural Basis for General Intelligence. Science, 289, 457-460. https://doi.org/10.1126/science.289.5478.457

Eberth, J., \& Sedlmeier, P. (2012). The Effects of Mindfulness Meditation: A Meta-Analysis. Mindfulness, 3, 174-189. https://doi.org/10.1007/s12671-012-0101-x

Eisenbeiss, S. A., Knippenberg, D. V., \& Fahrbach, C. M. (2015). Doing Well by Doing Good? Analyzing the Relationship between CEO Ethical Leadership and Firm Performance. Journal of Business Ethics, 128, 635-651.

https://doi.org/10.1007/s10551-014-2124-9

Evans, J. S. (2008). Dual-Processing Accounts of Reasoning, Judgment, and Social Cognition. Annual Review of Psychology, 59, 255-278. https://doi.org/10.1146/annurev.psych.59.103006.093629

Fan, W., Zhang, M., Zhang, J., \& Zhang, S. (2011). Considering the Cultural Commonalities and Particularities of Personality Research: CPAI and Its Cross-Cultural Applications. Acta Psychologica Sinica, 43, 1418-1429.

Farb, N. A., Segal, Z. V., Mayberg, H., Bean, J., Mckeon, D., Fatima, Z. et al. (2007). Attending to the Present: Mindfulness Meditation Reveals Distinct Neural Modes of SelfReference. Social Cognitive \& Affective Neuroscience, 2, 313-322. https://doi.org/10.1093/scan/nsm030

Fiocco, A. J., \& Mallya, S. (2015). The Importance of Cultivating Mindfulness for Cognitive and Emotional Well-Being in Late Life. Journal of Evidence-Based Complementary \& Alternative Medicine, 20, 35-40. https://doi.org/10.1177/2156587214553940

Flook, L., Goldberg, S. B., Pinger, L., Bonus, K., \& Davidson, R. J. (2013). Mindfulness for Teachers: A Pilot Study to Assess Effects on Stress, Burnout and Teaching Efficacy. Mind Brain \& Education, 7, 182-195. https://doi.org/10.1111/mbe.12026

Foster, S. L., \& Lloyd, P. J. (2007). Positive Psychology Principle Applied to Consulting Psychology at the Individual and Group Level. Consulting Psychology Journal, 59, 3040. https://doi.org/10.1037/1065-9293.59.1.30

Good, D. J., Lyddy, C. J., \& Glomb, T. M. (2016). Contemplating Mindfulness at Work: An Integrative Review. Journal of Management, 42, 877-880. https://doi.org/10.1177/0149206315617003

Goodie, A. S. (2003). The Effects of Control on Betting: Paradoxical Betting on Items of High Confidence with Low Value. Journal of Experimental Psychology Learning Memory \& Cognition, 29, 598-610. https://doi.org/10.1037/0278-7393.29.4.598 
Greene, J. D., Nystrom, L. E., Engell, A. D., Darley, J. M., \& Cohen, J. D. (2004). The Neural Bases of Cognitive Conflict and Control in Moral Judgment. Neuron, 44, 389400. https://doi.org/10.1016/j.neuron.2004.09.027

Hafenbrack, A. C., Kinias, Z., \& Barsade, S. G. (2014). Debiasing the Mind through Meditation Mindfulness and the Sunk-Cost Bias. Psychological Science, 25, 369-376. https://doi.org/10.1177/0956797613503853

Hogarth, R. M., Portell, M., Cuxart, A., \& Kolev, G. I. (2009). Emotion and Reason in Everyday Risk Perception. Journal of Behavioral Decision Making, 24, 202-222. https://doi.org/10.1002/bdm.689

Ivanovski, B., \& Malhi, G. S. (2007). The Psychological and Neurophysiological Concomitants of Mindfulness Forms of Meditation. Acta Neuropsychiatrica, 19, 76-91. https://doi.org/10.1111/j.1601-5215.2007.00175.x

Kabat-Zinn, J. (2003). Mindfulness-Based Interventions in Context: Past, Present, and Future. Clinical Psychology Science \& Practice, 10, 144-156. https://doi.org/10.1093/clipsy.bpg016

Kabat-Zinn, J., \& Hanh, T. N. (2009). Full Catastrophe Living: Using the Wisdom of Your Body and Mind to Face Stress, Pain, and Illness. New York, NY: Random House Publishing Group.

Keng, S. L., Smoski, M. J., \& Robins, C. J. (2011). Effects of Mindfulness on Psychological Health: A Review of Empirical Studies. Clinical Psychology Review, 31, 1041-1056. https://doi.org/10.1016/j.cpr.2011.04.006

Kiken, L. G., \& Shook, N. J. (2011). Looking up Mindfulness Increases Positive Judgments and Reduces Negativity Bias. Social Psychological \& Personality Science, 2, 425-431. https://doi.org/10.1177/1948550610396585

Kirk, U., Downar, J., \& Montague, P. R. (2011). Interoception Drives Increased Rational Decision-Making in Meditators Playing the Ultimatum Game. Frontiers in Neuroscience, 5, 1-11. https://doi.org/10.3389/fnins.2011.00049

Krishnakumar, S., \& Robinson, M. D. (2015). Maintaining an Even Keel: An Affect-Mediated Model of Mindfulness and Hostile Work Behavior. Emotion, 15, 579-589. https://doi.org/10.1037/emo0000060

Lakey, C. E., Campbell, W. K., Brown, K. W., \& Goodie, A. S. (2007a). Dispositional Mindfulness as a Predictor of the Severity of Gambling Outcomes. Personality \& Individual Differences, 43, 1698-1710. https://doi.org/10.1016/j.paid.2007.05.007

Lakey, C. E., Goodie, A. S., \& Campbell, W. K. (2007b). Frequent Card Playing and Pathological Gambling: The Utility of the Georgia Gambling Task and Iowa Gambling Task for Predicting Pathology. Journal of Gambling Studies, 23, 285-297. https://doi.org/10.1007/s10899-006-9034-4

Lazar, S. W., Kerr, C. E., Wasserman, R. H., Gray, J. R., Greve, D. N., Treadway, M. T. et al. (2005). Meditation Experience Is Associated with Increased Cortical Thickness. Neuroreport, 16, 1893-1897. https://doi.org/10.1097/01.wnr.0000186598.66243.19

Li, X., Huang, R., \& Zhou, X. (2015). The Impact of Incidental Emotion on Decision Making. Progress in Psychological Science, 23, 919-925.

Lippelt, D. P., Hommel, B., \& Colzato, L. S. (2014). Focused Attention, Open Monitoring and Loving Kindness Meditation: Effects on Attention, Conflict Monitoring, and Creativity-A Review. Frontiers in Psychology, 5, 1083. https://doi.org/10.3389/fpsyg.2014.01083

Liu, Y., Song, H., Kou, J., \& Zou, Z. (2014). Barriers to Decision Making among Substance Addicts: Behavioral Manifestations, Causes and Interventions. 
Lueke, A., \& Gibson, B. (2015). Mindfulness Meditation Reduces Implicit Age and Race Bias: The Role of Reduced Automaticity of Responding. Social Psychological and Personality Science, 6, 284-291. https://doi.org/10.1177/1948550614559651

Malinowski, P., \& Hui, J. L. (2015). Mindfulness at Work: Positive Affect, Hope, and Optimism Mediate the Relationship between Dispositional Mindfulness, Work Engagement, and Well-Being. Mindfulness, 6, 1250-1262. https://doi.org/10.1007/s12671-015-0388-5

Maréchal, J. C. (2010). Editor's Message: The Sunk Cost Fallacy of Deep Drilling. Hydrogeology Journal, 18, 287-289. https://doi.org/10.1007/s10040-009-0515-2

Mascaro, J. S., Rilling, J. K., Tenzin Negi, L., \& Raison, C. L. (2012). Compassion Meditation Enhances Empathic Accuracy and Related Neural Activity. Social Cognitive and Affective Neuroscience, 8, 48-55. https://doi.org/10.1093/scan/nss095

Mcclure, S. M., Laibson, D. I., Loewenstein, G., \& Cohen, J. D. (2004). Separate Neural Systems Value Immediate and Delayed Monetary Rewards. Science, 306, 503-507. https://doi.org/10.1126/science.1100907

Miao, Y., \& Wang, J. (2013). Mindfulness in the Field of Positive Psychology. Psychological Counselors, 8, 13-17.

Michel, A., Bosch, C., \& Rexroth, M. (2014). Mindfulness as a Cognitive-Emotional Segmentation Strategy: An Intervention Promoting Work-Life Balance. Journal of Occupational \& Organizational Psychology, 87, 733-754. https://doi.org/10.1111/joop.12072

Mirams, L., Poliakoff, E., Brown, R. J., \& Lloyd, D. M. (2013). Brief Body-Scan Meditation Practice Improves Somatosensory Perceptual Decision Making. Consciousness and Cognition, 22, 348-359. https://doi.org/10.1016/j.concog.2012.07.009

Mrazek, M. D., Franklin, M. S., Phillips, D. T., Baird, B., \& Schooler, J. W. (2013). Mindfulness Training Improves Working Memory Capacity and GRE Performance while Reducing Mind Wandering. Psychological Science, 24, 776-781. https://doi.org/10.1177/0956797612459659

Mrazek, M. D., Smallwood, J., \& Schooler, J. W. (2012). Mindfulness and Mind-Wandering: Finding Convergence through Opposing Constructs. Emotion, 12, 442-448. https://doi.org/10.1037/a0026678

Panno, A., Lauriola, M., \& Figner, B. (2013). Emotion Regulation and Risk Taking: Predicting Risky Choice in Deliberative Decision Making. Cognition \& Emotion, 27, 326334. https://doi.org/10.1080/02699931.2012.707642

Park, M. S., Moon, J. H., \& Kang, C. S. (2006). A Study on the Degree of Deliberation and Meditation of Cyber Poll Respondents for Nuclear-Related Decision Making. Annals of Nuclear Energy, 33, 163-169. https://doi.org/10.1016/j.anucene.2005.07.010

Pipe, T. B., Bortz, J. J., Dueck, A., Pendergast, D., Buchda, V., \& Summers, J. (2009). Nurse Leader Mindfulness Meditation Program for Stress Management: A Randomized Controlled Trial. Journal of Nursing Administration, 39, 130-137. https://doi.org/10.1097/NNA.0b013e31819894a0

Reb, J., \& Narayanan, J. (2014). The Influence of Mindful Attention on Value Claiming in Distributive Negotiations: Evidence from Four Laboratory Experiments. Mindfulness, 5, 756-766. https://doi.org/10.1007/s12671-013-0232-8

Rilling, J. K., \& Sanfey, A. G. (2011). The Neuroscience of Social Decision-Making. Annual Review of Psychology, 62, 23-48.

https://doi.org/10.1146/annurev.psych.121208.131647

Roche, M., Haar, J. M., \& Luthans, F. (2014). The Role of Mindfulness and Psychological Capital on the Well-Being of Leaders. Journal of Occupational Health Psychology, 19, 
476-489. https://doi.org/10.1037/a0037183

Rozin, P., \& Royzman, E. B. (2001). Negativity Bias, Negativity Dominance, and Contagion. Personality \& Social Psychology Review, 5, 296-320. https://doi.org/10.1207/S15327957PSPR0504_2

Ruedy, N. E., \& Schweitzer, M. E. (2010). In the Moment: The Effect of Mindfulness on Ethical Decision Making. Journal of Business Ethics, 95, 73-87. https://doi.org/10.1007/s10551-011-0796-y

Ruocco, A. C., \& Direkoglu, E. (2013). Delineating the Contributions of Sustained Attention and Working Memory to Individual Differences in Mindfulness. Personality \& Individual Differences, 54, 226-230. https://doi.org/10.1016/j.paid.2012.08.037

Saatcioglu, F. (2013). Regulation of Gene Expression by Yoga, Meditation and Related Practices: A Review of Recent Studies. Asian Journal of Psychiatry, 6, 74-77. https://doi.org/10.1016/j.ajp.2012.10.002

Sanfey, A. G. (2007). Social Decision-Making: Insights from Game Theory and Neuroscience. Science, 318, 598-602. https://doi.org/10.1126/science.1142996

Shapiro, S. L., Carlson, L. E., Astin, J. A., \& Freedman, B. (2006). Mechanisms of Mindfulness. Journal of Clinical Psychology, 62, 373-386. https://doi.org/10.1002/jclp.20237

Shapiro, S. L., Jazaieri, H., \& Goldin, P. R. (2012). Mindfulness-Based Stress Reduction Effects on Moral Reasoning and Decision Making. The Journal of Positive Psychology, 7, 504-515. https://doi.org/10.1080/17439760.2012.723732

Shonin, E., Gordon, W. V., Dunn, T. J., Singh, N. N., \& Griffiths, M. D. (2014). Meditation Awareness Training (mat) for Work-Related Wellbeing and Job Performance: A Randomised Controlled Trial. International Journal of Mental Health \& Addiction, 12, 806-823. https://doi.org/10.1007/s11469-014-9513-2

Simon, G. A. (2001). Rational Decision-Making in Business Organizations (the Nobel Memorial Lection Delivered in December 8, 1977). Psikhologicheskii Zhurnal, 22, 25 34.

Simon, H. A. (1987). Making Management Decisions: The Role of Intuition and Emotion. Academy of Management Executive, 1, 57-64. https://doi.org/10.5465/AME.1987.4275905

Smallwood, J., \& Schooler, J. W. (2015). The Science of Mind Wandering: Empirically Navigating the Stream of Consciousness. Annual Review of Psychology, 66, 487-518. https://doi.org/10.1146/annurev-psych-010814-015331

Standaert, N. (2015). Ignatian Visual Meditation in Seventeenth-Century China. In Meditation and Culture (pp. 24-35). London: Bloomsbury Publishing.

Tang, Y. Y., Hölzel, B. K., \& Posner, M. I. (2015). The Neuroscience of Mindfulness Meditation. Nature Reviews Neuroscience, 16, 213-225. https://doi.org/10.1038/nrn3916

Tang, Y. Y., Ma, Y., Fan, Y., Feng, H., Wang, J., Feng, S. et al. (2009). Central and Autonomic Nervous System Interaction Is Altered by Short-Term Meditation. Proceedings of the National Academy of Sciences of the United States of America, 106, 8865-8870. https://doi.org/10.1073/pnas.0904031106

Tang, Y. Y., Ma, Y., Wang, J., Fan, Y., Feng, S., Lu, Q. et al. (2007). Short-Term Meditation Training Improves Attention and Self-Regulation. Proceedings of the National Academy of Sciences of the United States of America, 104, 17152-17156. https://doi.org/10.1073/pnas.0707678104

Tate, E. B. (2007). The Multi-Faceted Nature of Mindfulness. Psychological Inquiry an International Journal for the Advancement of Psychological Theory, 18, 251-255.

Tversky, A., \& Kahneman, D. (2016). Advances in Prospect Theory: Cumulative Repre- 
sentation of Uncertainty. Journal of Risk and Uncertainty, 5, 297-323.

https://doi.org/10.1007/BF00122574

Wang, F., \& Huang, Y. (2011). Mindfulness and Brain Mechanisms. Advances in Psychological Science, 19, 1635-1644.

Wang, S., \& Zhao, M. (2016). Mindfulness on Anti-Relapse Therapy in Substance Addiction. Chinese Journal of Clinical Psychology, 24, 188-190.

Wang, Y., \& Jiang, C. (2016). The Biological Mechanism and Mental and Physical Health of Mindful Meditation. Chinese Journal of Mental Health, 30, 105-108.

Wasylkiw, L., Holton, J., Azar, R., \& Cook, W. (2015). The Impact of Mindfulness on Leadership Effectiveness in a Health Care Setting: A Pilot Study. Journal of Health Organization \& Management, 29, 893-911. https://doi.org/10.1108/JHOM-06-2014-0099

Waters, L., Barsky, A., Ridd, A., \& Allen, K. (2015). Contemplative Education: A Systematic, Evidence-Based Review of the Effect of Meditation Interventions in Schools. Educational Psychology Review, 27, 103-134. https://doi.org/10.1007/s10648-014-9258-2

Winters, K. C., Specker, S., \& Stinchfield, R. (2002). Measuring Pathological Gambling with the Diagnostic Interview for Gambling Severity (DIGS). In J. J. Marotta, J. A. Cornelius, \& W. R. Eadington (Eds.), The Downside: Problem and Pathological Gambling (pp. 143-148). Reno, NV: University of Nevada Press.

Wong, K. F. E., \& Kwong, J. Y. Y. (2007). The Role of Anticipated Regret in Escalation of Commitment. Journal of Applied Psychology, 92, 545-554.

https://doi.org/10.1037/0021-9010.92.2.545

Xu, W., \& Liu, X. (2013). Mindfulness Training to Improve the Study of Happiness. Chinese Journal of Mental Health, 27, 197-202.

Zhang, J., Song, J., \& Wang, Y. (2017). Mindfulness in the Workplace: A Review and Prospect of Research. Foreign Economics and Management, 39, 56-70. 